\title{
Antisolvent-assisted Controllable Growth of Fullerene Single Crystal Microwires for Organic Field Effect Transistors and Photodetectors
}

Xiaoming Zhao, ${ }^{1 \dagger}$ Tianjun Liu, ${ }^{1 \dagger}$ Yuzhou Cui, ${ }^{1}$ Xueyan Hou,,${ }^{1}$ Zilu Liu, ${ }^{2}$ Xingyi Dai, ${ }^{3}$ Jie Kong, ${ }^{3 *}$ Wenda Shi, ${ }^{1 *}$ T. John S. Dennis ${ }^{1 *}$

${ }^{1}$ School of Physics and Astronomy, Queen Mary University of London, Mile End Road, London E1 4NS, United Kingdom

${ }^{2}$ School of Biological and Chemical Sciences, Queen Mary University of London, Mile End Road, London E1 4NS, United Kingdom

${ }^{3}$ NPU-QMUL Joint Research Institute of Advanced Materials and Structures MOE Key Lab of Space Applied Physics and Chemistry, School of Science, Northwestern Polytechnical University, Xi'an, 710072, P. R. China

$\dagger \mathrm{X}$. Zhao and T. Liu have the equivalent contribution

Keywords: Organic field-effect transistors; fullerenes; single crystals; photodetectors

Abstract: There are only a few reported methods by which the size and morphology of organic single crystals for high-performance organic field-effect transistors (OFETs) or other devices can be controlled. Here, a facile solutionprocessed antisolvent vapor diffusion method was employed to grow millimeter-length $\mathrm{C}_{60}$ single crystal microwires directly in the solution. The size of the microwires can be controllably varied via the $\mathrm{C}_{60}$ concentration and/or the choice of antisolvent. OFETs fabricated from the as-produced microwires exhibit mobilities as high as $2.30 \mathrm{~cm}^{2} \mathrm{~V}^{-1}$ $\mathrm{s}^{-1}$. A clear relationship between crystal preparation condition and device performance is revealed whereby the lower the evaporation rate of antisolvent and/or the higher the 
$\mathrm{C}_{60}$ concentration, the higher the devices performance. Photodetectors based on our microwires give a responsivity that is an order of magnitude higher than those grown by drop-casting methods. This study provided a facile method for the crystal engineering of size-tunable millimeter-length $\mathrm{C}_{60}$ single crystals, and revealed the important influences of antisolvent to the $\mathrm{C}_{60}$ crystal size and the performance of devices based on them. We believe that our processing approach can be further exploited for a broad range of other organic semiconductors to achieve desirable single crystal size and morphology and thus desirable OFETs and photodetector performance.

Organic field-effect transistors (OFETs) based on one-dimensional ("1D”) morphological microstructures have attracted continuous attention in recent years owing to their unprecedented device performance, which present great promise for flexible, low-cost, and lightweight electronic devices including complementary circuits, ${ }^{1,2}$ displays, ${ }^{3,4}$ sensors, ${ }^{5-7}$ and photodetectors. ${ }^{8-10}$ Of these, photodetectors (which convert optical signals to electrical signals) are essential elements in highresolution imaging technique, light-wave communications, and optical interconnects. ${ }^{11-14}$

Among 1D microstructures, organic single-crystal microwires ("SCMWs"), being free of grain boundaries and molecular disorder, facilitate directional charge transport and exciton diffusion. ${ }^{15,16}$

High-performance OFETs based on SCMWs have been reported for various small conjugated molecules. For instance, OFETs based on Fullerene $\mathrm{C}_{60}$ needle-like single 
crystals exhibits electron mobilities exceeding $10 \mathrm{~cm}^{2} \mathrm{~V}^{-1} \mathrm{~s}^{-1},{ }^{17}$ which is one of the highest among OFETs based on solution-grown organic single crystals. Inspired by the high performance of the SCMWs, interest now is directed toward the controllable assembly of the crystals and the study of their photo-response properties. ${ }^{9}$

Until now, the most commonly used methods for fabricating organic singlecrystals are vacuum-deposition and solution-deposition techniques. However, these techniques have several drawbacks. Vacuum deposition has the disadvantages of being energy-consuming and a requirement for complex equipment. Solution-deposition techniques, including drop-casting, ${ }^{18}$ spin-coating, ${ }^{19,20}$ and dip coating ${ }^{21-23}$ have the disadvantage of involving a step in which the solvent is removed from the surface by evaporation - a kinetically controlled phenomenon. ${ }^{24-27}$ These have the effect that the microstructures of single crystals are not particularly controllable, resulting in poor reproducibility. ${ }^{28}$ Various post-treatment procedures have been widely employed to improve molecular surface organization after solution deposition such as thermal ${ }^{18,29}$ and solvent vapor annealing. ${ }^{30-34}$ These in turn had the disadvantage in that that posttreatment requires the preformation of a homogeneous and continuous film, which limits their applicability for device fabrication. Growing crystals directly in solutions avoids the negative effect caused by the substrate, which enables more finely tuning of the crystal morphology and thus achieve the desirable device performance.

In this article, we report a two-vial-based solution-processing method, antisolvent vapor diffusion (AVD), which permits modification of the self-assembly of organic semiconductors directly in the solution before transferring to substrates. In this method, 
we set $\mathrm{C}_{60}$ solutions of $m$-xylene in the inner vial and antisolvents including methanol $(\mathrm{MeOH})$, ethanol (EtOH) and isopropanol (IPA) in the outer vial. The slow solvent exchange between $m$-xylene and antisolvents via vapor diffusion enables gradual and highly controlled adjustment of the size of the crystals. The crystal size is finely tuned by varying the $\mathrm{C}_{60}$ concentrations together with using different antisolvents. Macroscopic $\mathrm{C}_{60}$ SCMWs with millimeter lengths were obtained through this method. The effect of antisolvent-induced variations in the crystal size (length, width and height) and crystallization behavior were studied by optical microscopy (OM), atomic force microscopy (AFM), scanned electron microscopy (SEM), transmission electron microscopy (TEM) and X-ray diffraction (XRD), as appropriate. OFETs are fabricated based on AVD-grown $\mathrm{C}_{60}$ SCMWs with a maximum electron mobility exceeding 2.30 $\mathrm{cm}^{2} \mathrm{~V}^{-1} \mathrm{~s}^{-1}$. NIR-photodetectors based on AVD-grown SCMWs present a responsivity an order of magnitude higher than those grown by drop-casting ("DC") method, indicating a high suitability of the AVD method for practical applications. This study provided a facile method for the crystal engineering of size-tunable millimeter-length $\mathrm{C}_{60}$ single crystals, and revealed the important influences of antisolvent to the $\mathrm{C}_{60}$ crystal size and the performance of devices based on them. We believe that our processing approach can be further exploited for a broad range of other organic semiconductors to achieve desirable single crystal size and morphology and thus desirable OFETs and photodetector performance.

Using an AVD crystallization strategy, we have succeeded in growing size-tunable millimeter-length $\mathrm{C}_{60}$ SCMWs. Figure 1a displays the setup and working mechanism 
of the two-vial-based AVD. During the process of AVD, a $\mathrm{C}_{60}$ solution in inner vial is exposed to an atmosphere of a saturated antisolvent vapor in an airtight container. The slow solvent exchange between the two solvents via vapor diffusion enables gradual, highly controlled adjustment of the solubility of the $\mathrm{C}_{60}$ molecules. Upon gradual solvent exchange, the solution in the inner vial became more dominant with antisolvents, which are poor solvents (with low solubility) for $\mathrm{C}_{60}$, thereby leading to self-assembly of the $\mathrm{C}_{60}$ molecules into SCMWs. After 5 days' growth, $\mathrm{C}_{60}$ SCMWs with millimeter length are achieved. The SCMWs obtained were then re-dispersed in hexane, producing a suspension well-suited for moving onto a substrate by pipette. After 24 hours' thermal annealing under vacuum to remove solvent molecules from the lattice structure, ${ }^{35}$ the samples can be used for microscopy imaging or device fabrication. Successful application of this method for crystallization depends on the judicious selection of solvents according to the intrinsic properties of the materials under study. $m$-xylene was used as the inner-vial solvent because it can induce $1 \mathrm{D}$ single crystal growth of $\mathrm{C}_{60} \cdot{ }^{17}$ Commonly-used poor solvents for $\mathrm{C}_{60}, \mathrm{IPA}, \mathrm{MeOH}$ and $\mathrm{EtOH}$, were used as outer-vial antisolvents.

Figure 1b-e presents the influence of $\mathrm{C}_{60}$ concentration, and the choice of antisolvents with different evaporation rates ("ERs"), on the AVD crystallization process. The crystal growth process can be divided into two stages - (i) nucleation and (ii) growth. According to the LaMer model, ${ }^{36,37}$ there are three stages in $\mathrm{C}_{60}$ crystal growth: nucleating aggregation (Stage 1), initial three-dimensional (3D) growth (Stage 2) and preferential one-dimensional (1D) growth (Stage 3). In Stage 1, when nucleation 
threshold is achieved, $\mathrm{C}_{60}$ molecules aggregated and combined with van der Waals interaction. In Stage 2, growth along the crystal height, length and width directions occurs simultaneously. In Stage 3 , driven by $\pi-\pi$ interactions, $\mathrm{C}_{60}$ stacks preferentially along the length direction and as such form tightly packed 1D chains. The two key factors exhibited in the kinetic growth model are (i) the duration of Stages 1 and 2 and (ii) the number-density of nuclei formed during Stage 1. These two factors are separately controlled by the $\mathrm{C}_{60}$ concentration and the choice of antisolvents.

Figure S1 presents X-Ray photoelectron spectroscopy (XPS) C1s spectrum of asprepared $\mathrm{C}_{60}$ single crystals. It shows that our $\mathrm{C}_{60}$ single crystals exhibit almost $100 \%$ carbon with binding energies at about $284.5 \mathrm{eV}(\mathrm{C}-\mathrm{C}) .{ }^{38} \mathrm{OM}$, SEM and AFM methods were employed to measure the length, width and height of the $\mathrm{C}_{60}$ SCMWs. The results are shown in Figure 2a-c and Figure S2-10 (Supporting Information). Table 1 summarizes dimensions of the $\mathrm{C}_{60}$ microwires prepared under different preparation conditions. The mean value and standard deviation of the dimensions are calculated based on some 40 crystals. We found that the length $L$, width $W$, and height $H$ of the $\mathrm{C}_{60} \mathrm{SCMWs}$ can be readily adjusted by tuning processing variables such as antisolvent varieties and $\mathrm{C}_{60}$ concentrations in $m$-xylene. Firstly, we found that $L, W$ and $H$ are all directly related to the $\mathrm{C}_{60}$ concentration; as $W$ and $H$ decrease, while $L$ increases with increasing $\mathrm{C}_{60}$ concentration irrespective of which antisolvent is employed. Figure 1b shows a direct correlation between the solution concentration and the nucleation rate whereby higher concentrations yield faster nucleation. The $\mathrm{C}_{60}$ solution with the highest concentration $\left(2 \mathrm{mg} \mathrm{mL}^{-1}\right)$ spent the shortest duration in Stages 1 and 2, resulting in the 
smallest crystal width and height. The reason for this is that in higher concentrations the total number of $\mathrm{C}_{60}$ growth units is greater than it is in lower concentration solution. Therefore, during the one-dimensional growth, longer microwires are achieved from higher concentration solutions. Conversely, the $\mathrm{C}_{60}$ solution with the lowest concentration $\left(0.2 \mathrm{mg} \mathrm{mL}^{-1}\right)$, and thereby the smallest number of $\mathrm{C}_{60}$ growth units, remained the longest time in Stages 1 and 2 and resulted in SCMWs with the largest width and height but the smallest length. Secondly, we found that the length of the SCMW may also be governed by the choice of the antisolvent. For example, at a constant $\mathrm{C}_{60}$ concentration of $2.0 \mathrm{mg} \mathrm{ml}^{-1}$, average $L=4.47,2.52$ and $1.31 \mathrm{~mm}, W=$ 1.07, 1.04 and $1.09 \mu \mathrm{m}$ and $H=0.89,1.01$ and 0.94 are observed when the antisolvent was IPA, EtOH and $\mathrm{MeOH}$, respectively. This observation results from the different ERs of these three antisolvents $(\mathrm{ER}$ relative to EtOH: $\mathrm{IPA}=0.78, \mathrm{EtOH}=1.0$ and $\mathrm{MeOH}=1.1) .{ }^{39}$ As shown in Figure 1c-f, the number density of nuclei is tuned by applying antisolvents with different ERs. At a fixed value of $\mathrm{C}_{60}$ concentration, the number density of nuclei increases with higher ER antisolvent (Figure 1d). By keeping the concentration, and thereby the number of $\mathrm{C}_{60}$ growth units constant, the final length of the microwires maybe shortened by applying antisolvents with higher ER (Table 1). This is a result of the increased number density of nuclei (i.e., the number of microwires as per Figure 1f). In summary, the advantage of the AVD process is that the crystal size can be fine-tuned in the solution by varying the $\mathrm{C}_{60}$ concentration and/or selecting the antisolvents with different evaporation rates. Varying the solution concentration 
controls the crystal three dimensional sizes while applying different antisolvents further tunes crystal length.

To gain more insight into the crystal structures of the $\mathrm{C}_{60}$ SCMWs, the samples were studied by XRD, the results of which are shown in Figure 2d and Figure S11. The XRD patterns can be indexed with a FCC crystal system, and the 200 reflection is missing. The extinction of 200 reflection is typical of pristine $\mathrm{FCC} \mathrm{C}_{60}$ crystals. ${ }^{40}$ The lattice constant of the of the $\mathrm{C}_{60}$ SCMWs is $a=1.414 \mathrm{~nm}$; which consistent with the value of $1.415 \mathrm{~nm}$ of pristine $\mathrm{C}_{60}$ crystals. $^{41}$ Further insight into the molecular organization is obtained by TEM of individual SCWMs and its corresponding selected area electron diffraction ("SAED") patterns. TEM image in Figure 2e reveals that the SCMWs are of uniform structure and the presence of discrete diffraction points in the SAED patterns (Figure 2f and Figure S12) is observed, indicating single crystallinity of the $1 \mathrm{D}$ object.

The high quality and macroscopic dimension of the as-grown millimeter-length SCMWs facilitates OFETs fabrication. This is because electrodes can be easily deposited perpendicular to the crystals with the support of a shadow mask (as opposed to the more common crystal-positioning under microscopy). As such, SCMW-based OFETs were constructed on n-octadecyltrimethoxysilane ("OTS") monolayermodified $\mathrm{SiO}_{2}(300 \mathrm{~nm}) / \mathrm{Si}$ substrates. A bottom-gated top-contact configuration was achieved by depositing Au as source and drain electrodes (Figure 3a). As shown in Figure $3 \mathbf{b}$, the channel length was $1 \mathrm{~mm}$. The crystals did not fully cover the channels. Therefore, the active channel width was measured from the contacting area of the 
crystals that cross the source and drain electrodes (as shown in Figure 3c). The saturation region electron mobilities of AVD-grown $\mathrm{C}_{60}$ SCMW OFETs based on varied $\mathrm{C}_{60}$ concentrations and antisolvents were tested under vacuum. The transfer and output characteristics of typical n-channel OFETs were observed (Figure 3d, e and Figure S13-15), showing excellent gate modulation. Charge carrier mobility plays a central role in semiconductor science and technology, because the efficiency of semiconductor devices generally improves as charge mobilities increase. ${ }^{42}$ The mobility was gate-bias dependent therefore we calculated the mobilities over the high gate voltage regime (40 to $80 \mathrm{~V}$ ), as suggested in the literature. ${ }^{43}$ OFET characteristics of $\mathrm{C}_{60}$ SCMWs obtained at different preparation conditions was summarized in Table 2. For comparison, OFETs based $\mathrm{C}_{60}$ needle-like crystals grown by conventional dropcasting method was also fabricated according to the literature. ${ }^{17}$ At the $\mathrm{C}_{60}$ concentration of $2.0 \mathrm{mg} \mathrm{mL}^{-1}$ with IPA as antisolvent, a maximum electron mobility $(\mu)$ of $2.30 \mathrm{~cm}^{2} \mathrm{~V}^{-1} \mathrm{~s}^{-1}$, on/off current ratio $\left(\mathrm{I}_{\mathrm{on}} / \mathrm{I}_{\mathrm{off}}\right)>10^{4}$, and threshold voltage $\left(V_{\mathrm{T}}\right)$ of 16.5 $\mathrm{V}$ were achieved (Figure 3d). At this condition, a total of 50 devices from the same fabrication batch were investigated, and the distribution histogram of the electron mobilities obtained is shown in Figure 3f. They all have mobilities over $1.90 \mathrm{~cm}^{2} \mathrm{~V}^{-1}$ $\mathrm{s}^{-1}$, yielding a high average mobility up to $2.11 \mathrm{~cm}^{2} \mathrm{~V}^{-1} \mathrm{~s}^{-1}$, which is better than the mobility $\left(0.78 \mathrm{~cm}^{2} \mathrm{~V}^{-1} \mathrm{~s}^{-1}\right)$ of OFET based $\mathrm{C}_{60}$ needle-like crystals grown by conventional drop-casting method as shown in Figure S16. Different antisolvents and concentrations of $\mathrm{C}_{60}$ in $m$-xylene were used for crystal growth to uncover the growth condition and mobility relationships as shown in Figure 3g. Firstly, it is seen that at 
constant $\mathrm{C}_{60}$ concentration, the average mobility of OFETs shows a decline when employing IPA, EtOH and $\mathrm{MeOH}$, respectively, as the antisolvent. This is due to their different ERs; whereby, lower ER antisolvent give slower solvent exchange between the two solvents via vapor diffusion. This enables gradual and highly controlled adjustment of the solubility of the molecules and produce high-quality crystals with lower defects. Secondly, it was found that, for constant antisolvent, $\mathrm{C}_{60}$ concentration in $m$-xylene plays an important role in device performance, whereby mobility increases with increasing $\mathrm{C}_{60}$ concentration. As discussed above, higher $\mathrm{C}_{60}$ concentrations induce thinner single crystals, which result in better interfacial contacts to the dielectric. ${ }^{44,45}$ Furthermore, thinner crystals would minimize the injection and extraction barriers of charge carriers. ${ }^{46}$ These are further evidenced by calculating the subthreshold swing (S.S.) and interface trap density ( $\left.N_{\mathrm{SS}}\right)$, which represent the interface quality and the trap behavior in OFETs. It is reported that the crystal quality plays an important role in device performance. ${ }^{47}$ As the interface control is the same for all devices, their different $S . S$. and $N_{\text {SS }}$ result from the different crystal quality. Therefore, the S.S. and $N_{\mathrm{SS}}$ here can represent the crystal quality of each device. Subthreshold swing and interface density of each OFETs are calculated according to the Equation (1) and Equation (2): ${ }^{48}$

$$
\begin{aligned}
& \text { S.S. }=\frac{d V_{G S}}{d I_{D S}} \\
& N_{S S}=\left[\frac{S \log (e)}{k T / q}-1\right] \frac{C_{i}}{q}
\end{aligned}
$$


Where $C_{\mathrm{i}}$ is the capacitance per unit area; $k$ is Boltzmann's constant, and $T$ is the absolute temperature, $I_{\mathrm{DS}}$ is the drain-source current, $V_{\mathrm{GS}}$ is the gate voltage . As shown in Table 2, OFETs based on $\mathrm{C}_{60}$ grown by IPA has the lowest $S . S$. and $N_{\mathrm{SS}}$, which further confirmed that the slower decrease in solubility allows for growth of materials with minimal crystalline defects and thus result in higher device performances. As such, not only the crystal size, but also device performance, is fine-tunable by the AVD method.

Curry et al. reported that $\mathrm{C}_{60}$ single crystal has a unique extended absorption in NIR region. ${ }^{49}$ Coupled with the excellent charge transport characteristics and the millimeter-scale infrastructures, $\mathrm{C}_{60} \mathrm{SCMWs}$ show significant promise for applications in NIR photodetectors. To investigate photo-response properties, two kinds of device were fabricated on silicon substrates with a $300 \mathrm{~nm}$ thick thermal oxide layer. The first used 1D AVD-grown $\mathrm{C}_{60}$ single crystals (IPA antisolvent: $\mathrm{C}_{60}$ concentration $=2.0 \mathrm{mg}$ $\left.\mathrm{mL}^{-1}\right)$. The second used a conventional drop-casting (DC) method. We refer to these as AVD-device and DC-device, respectively. Single crystals obtained by DC are very short (less than $200 \mu \mathrm{m}$ ) when compared to mm-length AVD-grown single crystals. Therefore, for comparison reasons, both devices were made with identical channel lengths of $20 \mu \mathrm{m}$ (as shown in the SEM images in insets of Figure 4a and b). The electrical properties were measured using a traditional two-terminal method. ${ }^{8}$ Photoresponse characteristics under NIR $(780 \mathrm{~nm})$ laser diodes with the power intensity of 1.5, 2.5 and $6.5 \mathrm{~mW} \mathrm{~cm}^{-2}$ are shown in Figure 4a, $\mathbf{c}$, e and $\mathbf{g}$ for AVD-device and Figure $4 \mathbf{b}, \mathbf{d}, \mathbf{f}$ and $\mathbf{h}$ for the DC-device and summarized in Table 3. 
Figure 4a and b shows typical current versus voltage curves of AVD and DC photodetectors in the dark and under laser illumination. The slight nonlinearity of the $I-V$ curves results from the work-function mismatch between $\mathrm{C}_{60}$ and the gold contacts used in our devices. A drastic increase in current under laser illumination is observed when compared to the current in the dark. These devices also revealed good lightcontrolled characteristics in that the conductivity increased significantly with the increase of illumination intensity. Interestingly, the AVD-device has a lower dark current than the DC-device, which is attributed to their different morphologies. The microwires of the AVD-device has a width of $\sim 0.9 \mu \mathrm{m}$. This is less than the $\sim 2.4 \mu \mathrm{m}$ width for the DC-device, which gives lower dark current in AVD device.

Photoresponsivity, $R$, is a key factor to identify the light-sensitive performance of photodetectors. $R$ is defined as the photocurrent generated per unit power of incident light on the effective area of a photodetector. To further evaluate the photo-response, we calculated photo-responsivity of AVD and DC-devices by the Equation (3): ${ }^{50}$

$$
R=\frac{I_{\text {light }}-I_{\text {dark }}}{P S}
$$

Where $I_{\text {light }}$ is the current when exposed to NIR light, $I_{\text {dark }}$ is the dark current, $P$ is the incident power density and $S$ is the effective illuminated area. The effective irradiated area is approximately $5.13 \mu \mathrm{m}^{2}$. The AVD photodetector has clearly a substantially higher performance than the DC-device. As depicted in Figure 4c and d, at an applied bias of $30 \mathrm{~V}$, under 1.5, 2.5 and $6.5 \mathrm{~mW} \mathrm{~cm}^{-2}$ laser illumination, AVD devices achieve responsivities of 82.6, 58.5 and 48.2 $\mathrm{A} \mathrm{W}^{-1}$ respectively. These are over 
one order magnitude higher than the responsivities of the corresponding DC-devices as shown in Table 3. Broad spectral detection is beneficial for extending the application range of photodetectors. The spectral photoresponse of the device at a bias of $30 \mathrm{~V}$ at wavelengths from 350 to $800 \mathrm{~nm}$ is displayed in Figure S17. The AVD photodetectors present broadband photo-response at wavelength from 350 to $800 \mathrm{~nm}$. The peak response is found at $450 \mathrm{~nm}$ with a responsitivity of about $112.5 \mathrm{~A} \mathrm{~W}^{-1}$. These results indicate an excellent performance of photodetectors based on our AVD grown $\mathrm{C}_{60}$ single crystals, which give more satisfactory values when compared with other reported photodetectors working under the similar conditions (Table 4). ${ }^{37,51-60}$ Furthermore, both AVD and DC photodetectors present good stability. As shown in Figure S18, both devices retained over $80 \%$ of their initial responsitivities after $240 \mathrm{~h}$ in $30 \%$ relative humidity at room temperature.

It has been reported that the device configuration had a drastic influence on the sensitivity of photodetectors: whereby channels with larger surface-to-volume ratio would yield higher responsivity. ${ }^{8}$ In our case, the $\mathrm{C}_{60}$ microwires grown by the AVD method have a higher surface-to-volume ratio than that produced by the DC method, which enables the AVD device to have higher performance. This is further confirmed by measuring several AVD devices with different surface to volume ratios as shown in Table S1. In addition, AVD device $\left(2.11 \mathrm{~cm}^{2} \mathrm{~V}^{-1} \mathrm{~s}^{-1}\right)$ has a higher charge mobility than DC device $\left(0.78 \mathrm{~cm}^{2} \mathrm{~V}^{-1} \mathrm{~s}^{-1}\right)$, which would lead to high efficiency of the extraction of photo-generated carriers, and result in the better performance of AVD than DC. ${ }^{53}$ It is 
also worth noting that at the same applied bias, the responsivity increases with lower power density, which demonstrates the high sensitivity of our NIR photodetectors.

Figure $4 \mathbf{e}$ and $\mathbf{f}$ displays the time-dependent current response of both photodetectors with the laser switched on and off at a fixed voltage of $30 \mathrm{~V}$. Under illumination of same power density, the "on" and "off" states keep the same current level for several cycles, indicating the excellent reversibility and stability of $\mathrm{C}_{60}$ crystal photodetectors. Furthermore, analysis of an enlarged photo-response process containing one rise and one reset (Figure $\mathbf{4 g}$ and $\mathbf{h}$ ) shows both the rising and reset time of the AVD devices are faster than those of the DC devices. In addition, the on/off ratio under $6.5 \mathrm{~mW} \mathrm{~cm}{ }^{-2}$ illumination is 59.2 for $\mathrm{AVD}$, which is more than 10 times higher than DC-device (5.6). The higher on/off ratio, faster detection time and the higher responsivity of AVD device further demonstrate the excellence of AVD crystallization method for practical applications.

In conclusion, a facile solution-processed antisolvent vapor diffusion method was employed to grow one-dimensional millimeter-length $\mathrm{C}_{60}$ crystal microwires directly in the solution. The size of the SCMWs is tunable simply by controlling the $\mathrm{C}_{60}$ concentration and the choice of antisolvent. The macroscopic dimension of as-produced SCMWs facilitates device fabrication, and OFETs based on them exhibit mobilities as high as $2.30 \mathrm{~cm}^{2} \mathrm{~V}^{-1} \mathrm{~s}^{-1}$. The relationship between crystal growth condition and device performance are revealed whereby lower antisolvent evaporation rates and/or higher $\mathrm{C}_{60}$ concentrations result in higher device performances. Photodetectors based on $\mathrm{C}_{60}$ single crystals by AVD method, shows better performance than the DC device with a 
fast, reversible, and stable photo-response, revealing the excellence of AVD method for practical applications. We believe that AVD method can be further exploited for a broad range of other organic semiconductors to achieve desirable single crystal size and morphology and thus desirable OFETs and photodetector performance.

\section{Experimental Section}

Materials: $\mathrm{C}_{60}$ with a purity of $99.95 \%$ was purchased from SES research, nOctadecyltrimethoxysilane (OTS) was purchased from Sigma Aldrich. $m$-xylene, IPA, $\mathrm{MeOH}, \mathrm{EtOH}$ and other solvents were purchased from Sigma Aldrich. All materials were used without further purification.

Wafer modification: Highly doped silicon substrates $\left(1 \mathrm{~cm}^{2}\right)$ with $300 \mathrm{~nm} \mathrm{SiO}_{2}$ were used for FET substrates. Before crystallization, the wafers were modified by n-OTS monolayer following previous report. ${ }^{61}$

Crystallization: Crystals were grown by a two-vial-based antisolvent vapor diffusion methods. Briefly, an inner vial containing $2 \mathrm{ml} m$-xylene solution of $\mathrm{C}_{60}$ was placed in a sealed outer vial, which contained about $2 \mathrm{ml}$ of antisolvent. The concentration of $\mathrm{C}_{60}$ was varied from $0.2 \mathrm{mg} \mathrm{ml}^{-1}$ to $2 \mathrm{mg} \mathrm{ml}^{-1}$ and IPA, EtOH and $\mathrm{MeOH}$ were respectively applied as antisolvent in this research. The inner vial was sealed by fine-meshed aluminum foil for slow vapor diffusion between the two solvents (Figure 1a). Upon gradual solvent exchange, the solution in the inner vial became more dominant with antisolvent, thereby leading to self-assembly of the molecules into MWs. After about 5 days, the exchange between the two solvents reached the equilibrium, resulting in 
complete assembly of the molecules, and precipitating down to the bottom of the inner vial. Then, the MWs were filtered from the solution and re-dispersed in hexane, producing a suspension well-suited for deposition on a substrate either for microscopy imaging or device fabrication.

Morphology Characterization and Crystallography: OM images were recorded using an Olympus BX 60 optical microscope. A NT-MDT Ntegra atomic force microscope in semicontact mode was used to characterize surface morphology of the MWs. SEM images were recorded by an FEI Inspect-F scanning electron microscope. TEM observations were performed with an ED configuration on a JEOL JEM-2010 transmission electron microscope with an accelerating voltage of $200 \mathrm{kV}$. XRD was performed by Siemens D5000 X-Ray Powder diffratometer. X-Ray photoelectron spectroscopy (XPS) spectra were obtained on a Thermo ESCALAB 250 spectrometer. OFET fabrication and characterization: OFETs were constructed in a bottom-gated configuration by depositing top-contact source and drain electrodes (50 $\mathrm{nm} \mathrm{Au})$, with channel lengths (L) of $1 \mathrm{~mm}$ for AVD OFETs and $20 \mu \mathrm{m}$ for DC OFETs and the channel width (W) was measured from the contacting area of the crystals that cross the S and D electrodes. Current-voltage characteristics of the devices were measured under a vacuum of $10^{-6}$ Torr on a Lake Shore model PS-100 tabletop cryogenic probe tation with a Keithley 4200-SCS semiconductor parameter analyzer. The measured capacitance of the OTS-modified $\mathrm{SiO}_{2} / \mathrm{Si}$ substrates was $11 \mathrm{nF} \mathrm{cm} \mathrm{cm}^{-2}$. The field-effect mobility was calculated in the saturation regime by using the equation $I_{\mathrm{DS}}=$ $\left(\mu W C_{i} / 2 L\right)\left(V_{\mathrm{G}}-V_{\mathrm{T}}\right)^{2}$, where $I_{D S}$ is the drain-source current, $\mu$ is the field-effect 
mobility, $W$ is the channel width, $L$ is the channel length, $C_{\mathrm{i}}$ is the capacitance per unit area of the gate dielectric layer, $V_{\mathrm{G}}$ is the gate voltage and $V_{\mathrm{T}}$ is the threshold voltage. Photodetector Fabrication and Photoresponse Measurement: Photodetectors were fabricated by dispersing MWs on silicon wafers with a $300 \mathrm{~nm}$ thick thermal oxide layer. The electrical contacts to individual MW were defined by copper grid shadow mask with the typical gap of $20 \mu \mathrm{m}$, and subsequently $50 \mathrm{~nm}$ Au was evaporated. Photoresponse measurements were performed on the same Lake Shore model PS-100 tabletop cryogenic probe tation by two-terminal mode with an applied bias of $30 \mathrm{~V}$ at room temperature. The parameters were analyzed using a Keithley 4200-SCS semiconductor characterization system. Laser diodes with different power densities $\left(1.5,2.5\right.$ and $\left.6.5 \mathrm{~mW} \mathrm{~cm}^{-2}\right)$ and wavelength $(350,370,400,420,450,470,500,520$, $550,570,590,600,620,650,680,700,720,740,750,760,780$ and $800 \mathrm{~nm}$ ) were used to illuminate the devices to initiate the photocurrent.

Long-Term Stability Measurement: The photodetectors were put in a Linpin Temperature Humidity Test Chamber with temperature and relative humidity of $23^{\circ} \mathrm{C}$ and $30 \%$, respectively. The photo-response of the photodetectors were measured every 5 hours by the method mentioned above. 


\section{ASSOCIATED CONTENT}

\section{Supporting Information.}

OM, SEM, AFM roughness analysis images, XRD patterns, SAED patterns and OFET transfer characteristics of MWs grown by AVD method at different conditions. Characteristics of AVD photodetectors based on $\mathrm{C}_{60}$ SCMWs with different surface-tovolume ratio.

\section{Graphical Abstract}

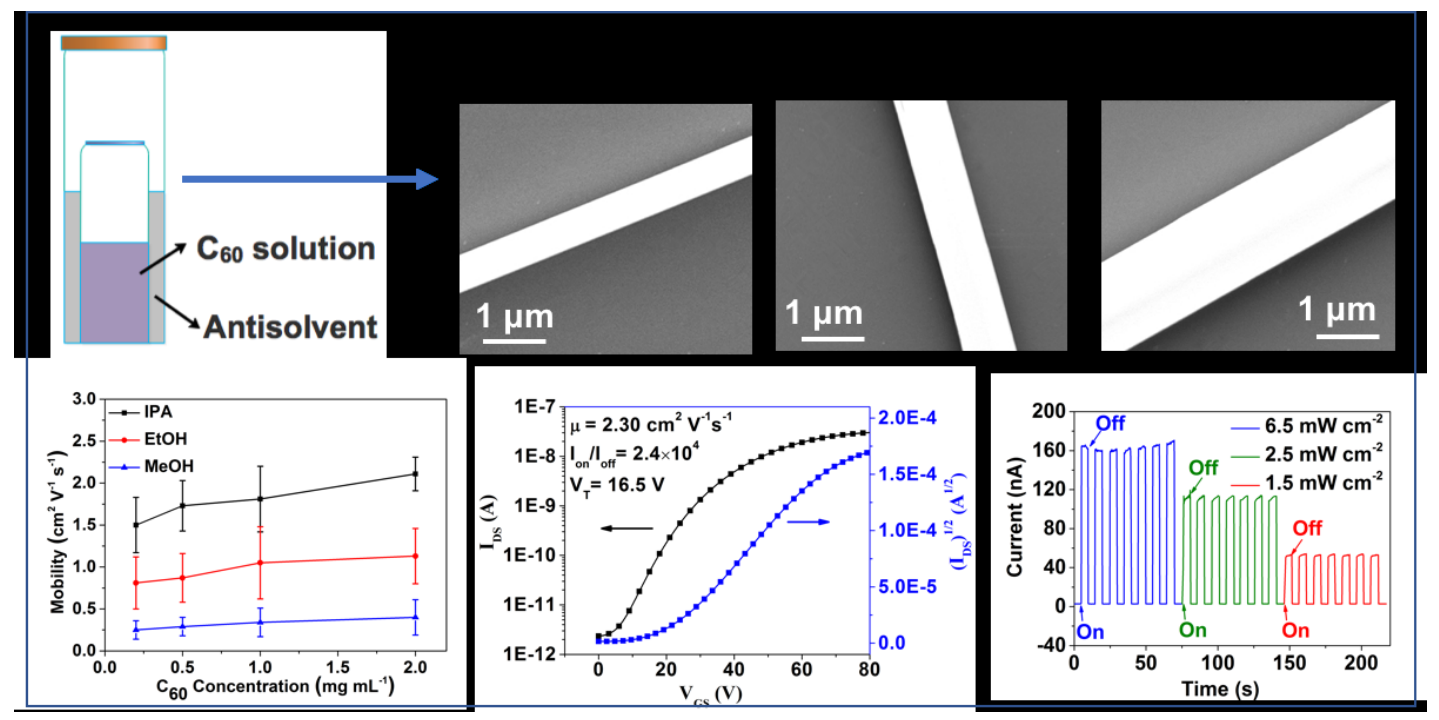

A facile solution-processed antisolvent vapor diffusion method was employed to grow millimeter-length $\mathrm{C}_{60}$ single crystal microwires directly in the solution. The size of the microwires may be controllably varied via the $\mathrm{C}_{60}$ concentration and/or the choice of antisolvent. OFETs fabricated from the as-produced microwires exhibit mobilities as high as $2.30 \mathrm{~cm}^{2} \mathrm{~V}^{-1} \mathrm{~s}^{-1}$. 


\section{AUTHOR INFORMATION}

\section{Corresponding Author}

*Email: T. J. S. Dennis: j.dennis@qmul.ac.uk; W. Shi: w.shi@qmul.ac.uk; J. Kong: kongjie@nwpu.edu.cn.

\section{Author Contributions}

The manuscript was written through contributions of all authors. All authors have given approval to the final version of the manuscript.

$\dagger$ These authors are $\mathrm{PhD}$ students who contributed equally to this work; albeit each leading a different aspect.

\section{Notes}

The authors declare no competing financial interest.

\section{ACKNOWLEDGMENT}

The authors thank the kind help of Dr. Dabiao Liu (QMUL) for the experimental support. X. Zhao, T. Liu, W. Shi, X. Hou and Z. Liu each thank the China Scholarship Council for funding. 
1 H. Yan, Z. Chen, Y. Zheng, C. Newman, J. R. Quinn, F. Dötz, M. Kastler and A. Facchetti, Nature, 2009, 457, 679-686.

2 B. Crone, A. Dodabalapur, Y.-Y. Lin, R. W. Filas, Z. Bao, A. LaDuca, R. Sarpeshkar, H. E. Katz and W. Li, Nature, 2000, 403, 521-523.

3 G. H. Gelinck, H. E. A. Huitema, E. van Veenendaal, E. Cantatore, L. Schrijnemakers, J. B. P. H. van der Putten, T. C. T. Geuns, M. Beenhakkers, J. B. Giesbers and B.-H. Huisman, Nat. Mater., 2004, 3, 106-110.

4 J. A. Rogers, Z. Bao, K. Baldwin, A. Dodabalapur, B. Crone, V. R. Raju, V. Kuck, H. Katz, K. Amundson and J. Ewing, Proc. Natl. Acad. Sci., 2001, 98, $4835-4840$.

5 S. C. B. Mannsfeld, B. C. K. Tee, R. M. Stoltenberg, C. V. H. H. Chen, S. Barman, B. V. O. Muir, A. N. Sokolov, C. Reese and Z. Bao, Nat. Mater., 2010, 9, 859-864.

6 A. N. Sokolov, M. E. Roberts, O. B. Johnson, Y. Cao and Z. Bao, Adv. Mater, 2010, 22, 2349-2353.

7 T. Sekitani, T. Yokota, U. Zschieschang, H. Klauk, S. Bauer, K. Takeuchi, M. Takamiya, T. Sakurai and T. Someya, Science (80-. )., 2009, 326, 1516-1519.

8 Z. Wang, M. Safdar, C. Jiang and J. He, Nano Lett., 2012, 12, 4715-4721. 
9 S. Schuler, D. Schall, D. Neumaier, L. Dobusch, O. Bethge, B. Schwarz, M. Krall and T. Mueller, Nano Lett., 2016, 16, 7107-7112.

10 J. S. Jie, W. J. Zhang, Y. Jiang, X. M. Meng, Y. Q. Li and S. T. Lee, Nano Lett., 2006, 6, 1887-1892.

11 Z. Fan, J. C. Ho, Z. A. Jacobson, H. Razavi and A. Javey, Proc. Natl. Acad. Sci., 2008, 105, 11066-11070.

12 J. Wang, M. S. Gudiksen, X. Duan, Y. Cui and C. M. Lieber, Science (80-. ), 2001, 293, 1455-1457.

13 C. Soci, A. Zhang, B. Xiang, S. A. Dayeh, D. P. R. Aplin, J. Park, X. Y. Bao, Y.-H. Lo and D. Wang, Nano Lett., 2007, 7, 1003-1009.

14 J.-J. Wang, F.-F. Cao, L. Jiang, Y.-G. Guo, W.-P. Hu and L.-J. Wan, J. Am. Chem. Soc., 2009, 131, 15602-15603.

15 J. H. Oh, H. W. Lee, S. Mannsfeld, R. M. Stoltenberg, E. Jung, Y. W. Jin, J. M. Kim, J.-B. Yoo and Z. Bao, Proc. Natl. Acad. Sci., 2009, 106, 6065-6070.

16 W. Jiang, Y. Zhou, H. Geng, S. Jiang, S. Yan, W. Hu, Z. Wang, Z. Shuai and J. Pei, J. Am. Chem. Soc., 2011, 133, 1-3.

17 H. Li, B. C. K. Tee, J. J. Cha, Y. Cui, J. W. Chung, S. Y. Lee and Z. Bao, J. Am. Chem. Soc., 2012, 134, 2760-2765.

18 V. Palermo and P. Samorì, Angew. Chemie - Int. Ed., 2007, 46, 4428-4432. 
19 V. Biju, M. Micic, D. Hu and H. P. Lu, J. Am. Chem. Soc., 2004, 126, $9374-$ 9381.

20 H. L. Yip, H. Ma, A. K. Y. Jen, J. Dong and B. A. Parviz, J. Am. Chem. Soc., 2006, 128, 5672-5679.

21 N. Liu, Y. Zhou, L. Wang, J. Peng, J. Wang, J. Pei and Y. Cao, Langmuir, 2009, 25, 665-671.

22 R. Dabirian, X. Feng, L. Ortolani, A. Liscio, V. Morandi, K. Mullen, P. Samori and V. Palermo, Phys. Chem. Chem. Phys., 2010, 12, 4473-4480.

23 L. Li, P. Gao, K. C. Schuermann, S. Ostendorp, W. Wang, C. Du, Y. Lei, H. Fuchs, L. De Cola, K. Müllen and L. Chi, J. Am. Chem. Soc., 2010, 132, 88078809.

24 P. C. Ohara, J. R. Heath and W. M. Gelbart, Angew. Chemie (International Ed. English), 1997, 36, 1078-1080.

25 P. Müller-Buschbaum, R. Gebhardt, E. Maurer, E. Bauer, R. Gehrke and W. Doster, Biomacromolecules, 2006, 7, 1773-1780.

26 S. Herminghaus, K. Jacobs, K. Mecke, J. Bischof, A. Fery, M. Ibn-Elhaj and S. Schlagowski, Science (80-. )., 1998, 282, 916-919.

27 S. Wang, L. Dössel, A. Mavrinskiy, P. Gao, X. Feng, W. Pisula and K. Müllen, Small, 2011, 7, 2841-2846. 
H. Li, C. Fan, M. Vosgueritchian, B. C.-K. Tee and H. Chen, J. Mater. Chem. C, 2014, 2, 3617-3624.

29 P. Samorí, H. Engelkamp, P. A. J. De Witte, A. E. Rowan, R. J. M. Nolte and J. P. Rabe, Adv. Mater., 2005, 17, 1265-1268.

30 G. De Luca, A. Liscio, P. Maccagnani, F. Nolde, V. Palermo, K. Müllen and P. Samori, Adv. Funct. Mater., 2007, 17, 3791-3798.

31 J. C. Conboy, E. J. C. Olson, D. M. Adams, J. Kerimo, A. Zaban, B. A. Gregg and P. F. Barbara, J. Phys. Chem. B, 1998, 102, 4516-4525.

32 B. A. Gregg, J. Phys. Chem., 1996, 100, 852-859.

33 G. De Luca, A. Liscio, F. Nolde, L. M. Scolaro, V. Palermo, K. Müllen and P. Samorì, Soft Matter, 2008, 4, 2064.

34 K. C. Dickey, J. E. Anthony and Y. L. Loo, Adv. Mater., 2006, 18, 1721-1726.

35 M. F. Meidine, P. B. Hitchcock, H. W. Kroto, R. Taylor and D. R. M. Walton, J. Chem. Soc. Commun., 1992, 1534-1537.

36 V. LaMer and R. Dinegar, J. Am. Chem. ..., 1950, 72, 4847-4854.

37 L. Wei, J. Yao and H. Fu, ACS Nano, 2013, 7, 7573-7582.

38 P. Song, H. Liu, Y. Shen, B. Du, Z. Fang and Y. Wu, J. Mater. Chem., 2009, 19, 1305. 
40 K. Miyazawa and Y. Kuwasaki, J. Mater. ..., 2002, 17, 83-88.

41 W. I. F. David, R. M. Ibberson, J. C. Matthewman, K. Prassides, T. J. S.

Dennis, J. P. Hare, H. W. Kroto, R. Taylor and D. R. M. Walton, Nature, 1991, 353, 147-149.

42 H. H. Choi, K. Cho, C. D. Frisbie, H. Sirringhaus and V. Podzorov, Nat. Mater., 2017, 17, 2-7.

43 I. McCulloch, A. Salleo and M. Chabinyc, Science (80-. )., 2016, 352, 15211522.

44 A. L. Briseno, R. J. Tseng, M. M. Ling, E. H. L. Falcao, Y. Yang, F. Wudl and Z. Bao, Adv. Mater., 2006, 18, 2320-2324.

45 L. Zang, Y. Che and J. S. Moore, Acc. Chem. Res., 2008, 41, 1596-1608.

46 J. Wang, T. Liu, J. Dong, M. Li, J. He and C. Jiang, Small, , DOI:10.1002/smll.201700456.

47 K. Y. Wu, C. T. Hsieh, L. H. Wang, C. H. Hsu, S. T. Chang, S. T. Lan, Y. F. Huang, Y. M. Chen and C. L. Wang, Cryst. Growth Des., 2016, 16, 61606166.

48 L. S. Tsai, C. H. Wang, W. Y. Chen, W. C. Wang and J. Hwang, Org. Electron. physics, Mater. Appl., 2010, 11, 123-126. 
Stolojan, H. W. Kroto and S. R. P. Silva, J. Mater. Chem., 2006, 16, 3715.

50 X. Gu, M. Zhang, F. Meng, X. Zhang, Y. Chen and S. Ruan, Appl. Surf. Sci., 2014, 307, 20-23.

51 Y. Y. Noh, D. Y. Kim and K. Yase, J. Appl. Phys., , DOI:10.1063/1.2061892.

52 T. P. I. Saragi, J. Londenberg and J. Salbeck, 2007.

53 J. Wang, F. Liu, G. Wang, L. Wang and C. Jiang, Org. Electron., 2016, 38, $158-163$.

54 G. A. O’Brien, A. J. Quinn, D. A. Tanner and G. Redmond, Adv. Mater., 2006, 18, 2379-2383.

55 Y. Zhang, T. Liu, B. Meng, X. Li, G. Liang, X. Hu and Q. J. Wang, Nat. Commun., 2013, 4, 1811.

56 M. Ding, D. Zhao, B. Yao, Q. Qiao and X. Xu, Appl. Phys. A Mater. Sci. Process., 2014, 118, 1267-1271.

57 M. Ding, D. Zhao, B. Yao, Z. Li and X. Xu, RSC Adv., 2015, 5, 908-912.

58 T. Zhai, X. Fang, M. Liao, X. Xu, L. Li, B. Liu, Y. Koide, Y. Ma, J. Yao, Y. Bando and D. Golberg, ACS Nano, 2010, 4, 1596-1602. 
59 O. Lupan, F. Schütt, V. Postica, D. Smazna, Y. K. Mishra and R. Adelung, Sci. Rep., , DOI:10.1038/s41598-017-14544-0.

60 Y. F. Wang, F. D. Qu, J. R. Zhou, W. Bin Guo, W. Dong, C. X. Liu and S. P. Ruan, Chinese Phys. Lett., , DOI:10.1088/0256-307X/32/8/088504.

61 Y. Ito, A. A. Virkar, S. Mannsfeld, H. O. Joon, M. Toney, J. Locklin and Z. Bao, J. Am. Chem. Soc., 2009, 131, 9396-9404.

62 Y.-Y. Noh, D.-Y. Kim and K. Yase, J. Appl. Phys., 2005, 98, 74505.

63 J. Wang, F. Liu, G. Wang, L. Wang and C. Jiang, Org. Electron., 2016, 38, $158-163$ 
(a)
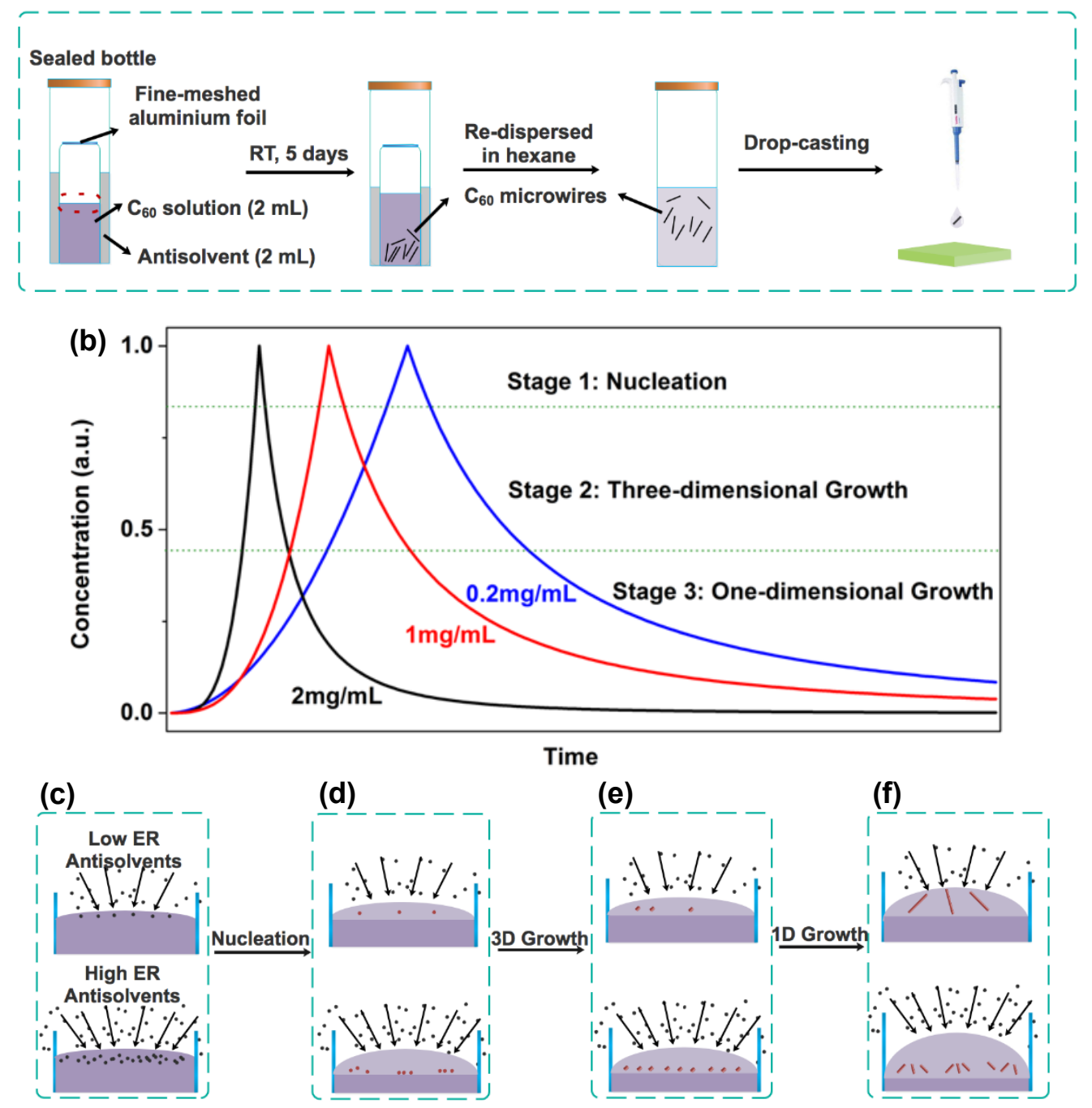

Figure 1 (a) Schematic diagram of $\mathrm{C}_{60} \mathrm{SCMWs}$ grown by AVD method. (b) LaMer model for the growth of microwires at different $\mathrm{C}_{60}$ concentrations. (c) Vapor diffusion of antisolvent to induce solvent exchange between $m$-xylene and antisolvent. (d) Crystal nucleation at the solvent exchange interface. (e) Initial 3D growth of nucleation. (f) Preferential 1D growth to form miscrowires. 

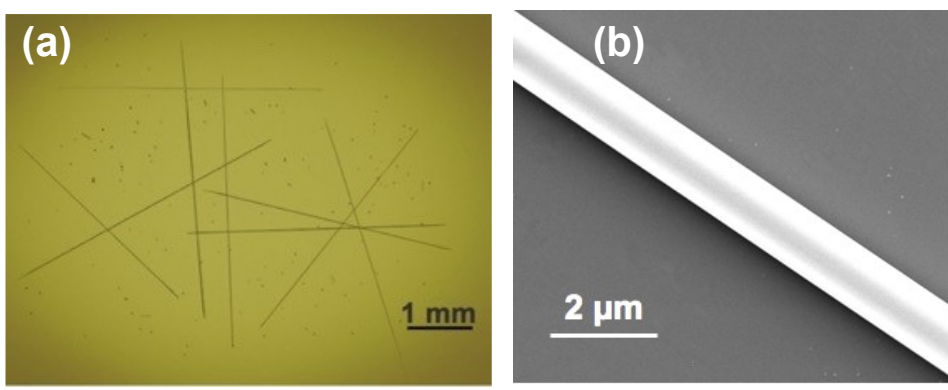

(d)

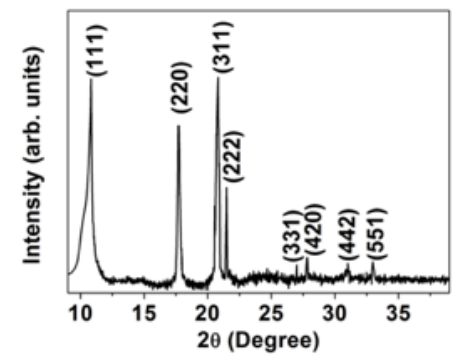

(e)

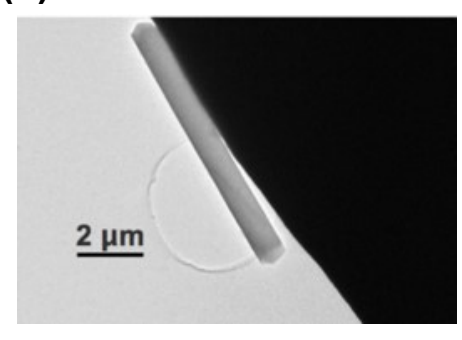

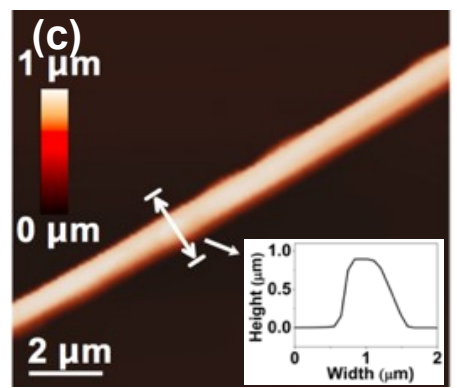

(f)

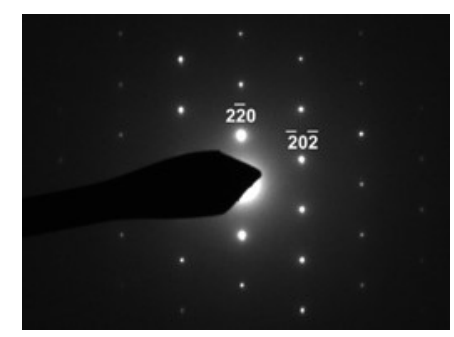

Figure 2 (a) OM, (b) SEM, (c) AFM (inset: selected area roughness analysis) images of $\mathrm{C}_{60}$ single crystals grown by AVD method at a $\mathrm{C}_{60}$ concentration of $2 \mathrm{mg} \mathrm{mL}^{-1}$ with IPA as antisolvent. (d) XRD pattern and (e)TEM image with corresponding (f) SAED pattern of vacuum-annealed FCC $\mathrm{C}_{60}$ single crystals grown by AVD method at a $\mathrm{C}_{60}$ concentration of $2 \mathrm{mg} \mathrm{ml}^{-1}$ with IPA as antisolvent. 
(a)

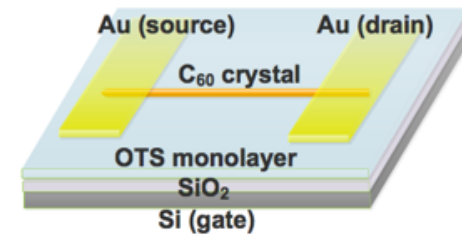

(d)

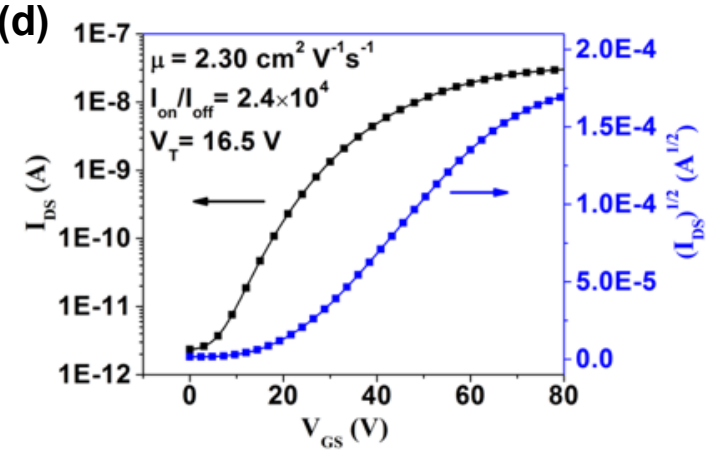

(f)

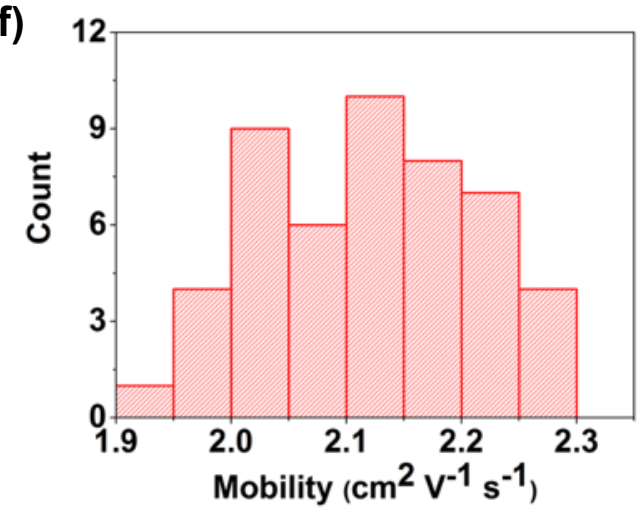

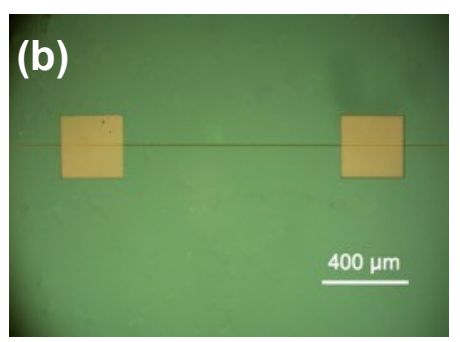
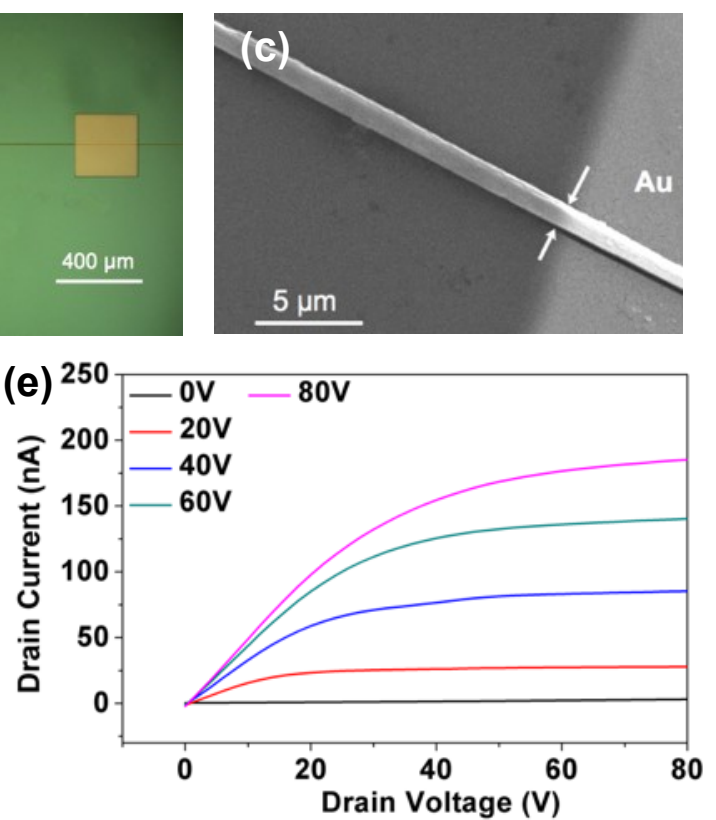

(g)

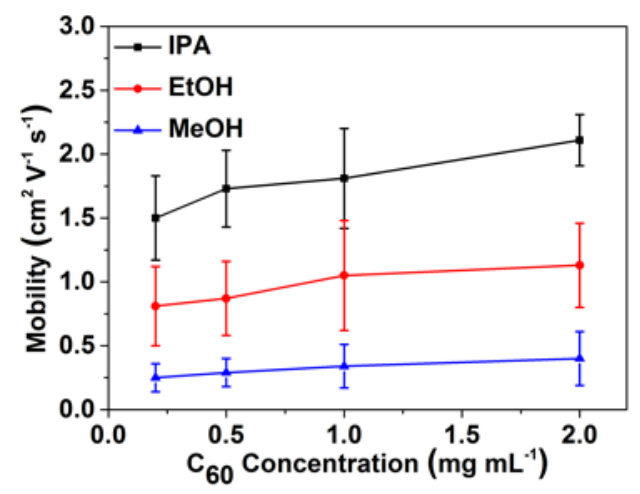

Figure 3 (a) Schematic of a typical device; (b) OM image showing $\mathrm{C}_{60}$ MWs between source $\mathrm{S}$ and drain D electrodes, channel length $L$ was measured from the real channel length and channel width (W) was measured from the contacting area of the crystals that cross the electrodes shown in the (c) SEM image. Typical (d) transfer and (e) output characteristics and (f) mobility distribution histogram of the FETs based on $\mathrm{C}_{60}$ MWs grown by AVD method at a solution concentration of $2.0 \mathrm{mg} \mathrm{ml}^{-1}$ with IPA as antisolvent; (e) OFET mobilities as a function of the $\mathrm{C}_{60}$ concentrations with different antisolvents. 

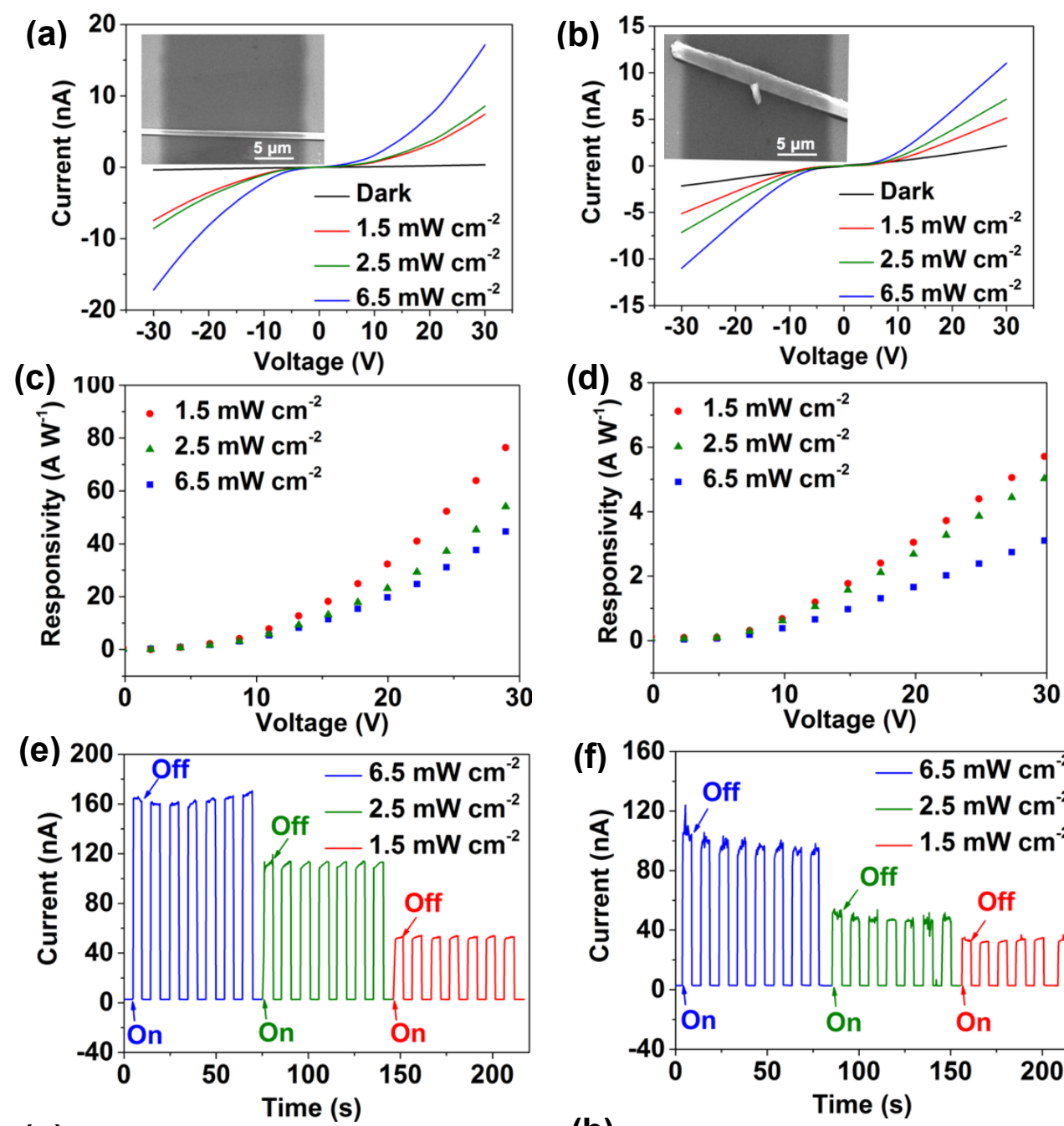

(g)

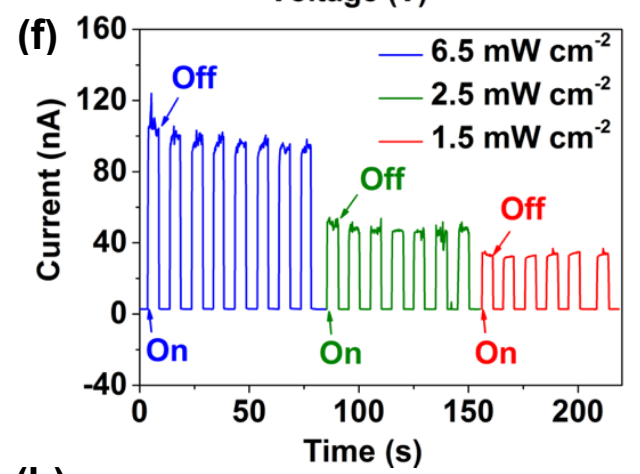

(h)
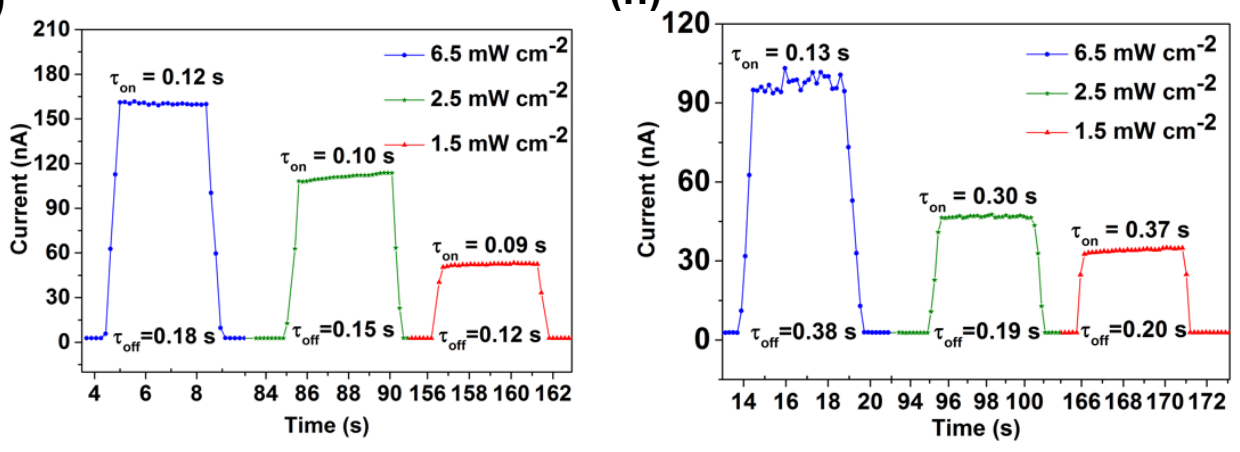

Figure 4 Photo-response characteristics of $\mathrm{C}_{60}$ single crystal devices, grown by the $\operatorname{AVD}(a, b, c, d)$ and DC (e,f,g,h) methods respectively. (a, b) I-V curves under dark condition and illuminated by NIR lasers. (c, d) Responsivity change with the laser power at different gate bias. (e, f) Time-dependent photocurrent response with the lasers 
on and off at the voltage of $30 \mathrm{~V} .(\mathrm{g}, \mathrm{h})$ Enlarged portions of one response and reset process under different laser powers. 
Table 1 Average sizes of $\mathrm{C}_{60}$ single crystal microwires obtained under different preparation conditions. Each value is calculated based on 40 crystals.

\begin{tabular}{|c|c|c|c|c|}
\hline & $\mathrm{C}_{\mathrm{C} 60}$ & & & \\
\hline Antisolvent & $\left(\mathrm{mg} \mathrm{mL}^{-1}\right)$ & $\mathrm{L}(\mathrm{mm})$ & W (um) & H (um) \\
\hline \multirow[t]{4}{*}{ IPA } & 2.0 & $4.47 \pm 0.53$ & $1.07 \pm 0.16$ & $0.89 \pm 0.15$ \\
\hline & 1.0 & $3.76 \pm 0.54$ & $1.31 \pm 0.27$ & $1.20 \pm 0.32$ \\
\hline & 0.5 & $3.53 \pm 0.40$ & $2.06 \pm 0.41$ & $2.07 \pm 0.45$ \\
\hline & 0.2 & $3.15 \pm 0.34$ & $2.45 \pm 0.43$ & $2.40 \pm 0.43$ \\
\hline \multirow[t]{4}{*}{$\mathrm{EtOH}$} & 2.0 & $2.52 \pm 0.62$ & $1.04 \pm 0.19$ & $1.01 \pm 0.13$ \\
\hline & 1.0 & $2.31 \pm 0.60$ & $1.29 \pm 0.30$ & $1.25 \pm 0.41$ \\
\hline & 0.5 & $2.17 \pm 0.49$ & $2.10 \pm 0.41$ & $2.15 \pm 0.55$ \\
\hline & 0.2 & $2.05 \pm 0.34$ & $2.59 \pm 0.50$ & $2.67 \pm 0.57$ \\
\hline \multirow[t]{4}{*}{$\mathrm{MeOH}$} & 2.0 & $1.51 \pm 0.23$ & $1.09 \pm 0.20$ & $0.94 \pm 0.17$ \\
\hline & 1.0 & $1.36 \pm 0.33$ & $1.32 \pm 0.31$ & $1.19 \pm 0.29$ \\
\hline & 0.5 & $1.25 \pm 0.20$ & $2.11 \pm 0.31$ & $2.11 \pm 0.38$ \\
\hline & 0.2 & $1.11 \pm 0.18$ & $2.53 \pm 0.53$ & $2.47 \pm 0.53$ \\
\hline
\end{tabular}


Table 2 OFET device performances of $\mathrm{C}_{60}$ single crystal microwires obtained under different preparation conditions. Each value is calculated based 50 devices.

\begin{tabular}{|c|c|c|c|c|c|c|}
\hline \multirow{3}{*}{ Antisolvent } & \multirow[b]{3}{*}{$\left(\mathrm{mg} \mathrm{mL}^{-1}\right)$} & \multirow[b]{3}{*}{$\left(\mathrm{cm}^{2} \mathrm{~V}^{-1} \mathrm{~s}^{-1}\right)$} & \multirow{3}{*}{$\begin{array}{l}\mathrm{I}_{\mathrm{on}} / \mathrm{I}_{\mathrm{off}} \\
\left(10^{4}\right)\end{array}$} & \multirow{3}{*}{$\begin{array}{l}\mathrm{V}_{\mathrm{T}} \\
(\mathrm{V})\end{array}$} & \multirow{3}{*}{$\begin{array}{c}\text { S.S. } \\
\text { (V/decade) }\end{array}$} & \multirow{3}{*}{$\begin{array}{c}\text { Trap Density } \\
\left(\times 10^{12} \mathrm{~cm}^{-2} \mathrm{eV}^{-1}\right)\end{array}$} \\
\hline & & & & & & \\
\hline & & & & & & \\
\hline \multirow[t]{4}{*}{ IPA } & 2.0 & $2.10 \pm 0.20$ & $2.4 \pm 0.16$ & $15.3 \pm 2.5$ & $7.42 \pm 1.1$ & $9.36 \pm 1.3$ \\
\hline & 1.0 & $1.81 \pm 0.39$ & $1.5 \pm 0.21$ & $14.7 \pm 2.7$ & $7.93 \pm 1.6$ & $10.12 \pm 1.3$ \\
\hline & 0.5 & $1.73 \pm 0.30$ & $2.8 \pm 0.19$ & $15.9 \pm 5.3$ & $8.38 \pm 1.2$ & $11.34 \pm 1.4$ \\
\hline & 0.2 & $1.50 \pm 0.33$ & $1.4 \pm 0.13$ & $13.6 \pm 3.1$ & $8.90 \pm 1.1$ & $12.31 \pm 1.7$ \\
\hline \multirow[t]{4}{*}{$\mathrm{EtOH}$} & 2.0 & $1.13 \pm 0.33$ & $1.2 \pm 0.23$ & $12.6 \pm 1.6$ & $9.99 \pm 2.1$ & $12.62 \pm 2.2$ \\
\hline & 1.0 & $1.05 \pm 0.43$ & $1.3 \pm 0.09$ & $12.3 \pm 1.1$ & $10.67 \pm 2.3$ & $13.48 \pm 2.9$ \\
\hline & 0.5 & $0.87 \pm 0.29$ & $1.3 \pm 0.16$ & $11.4 \pm 2.2$ & $11.00 \pm 2.9$ & $13.91 \pm 2.7$ \\
\hline & 0.2 & $0.81 \pm 0.31$ & $1.4 \pm 0.13$ & $17.1 \pm 4.4$ & $11.23 \pm 2.2$ & $14.23 \pm 2.8$ \\
\hline \multirow[t]{4}{*}{$\mathrm{MeOH}$} & 2.0 & $0.40 \pm 0.21$ & $1.4 \pm 0.11$ & $16.7 \pm 3.9$ & $14.37 \pm 3.4$ & $18.19 \pm 3.4$ \\
\hline & 1.0 & $0.34 \pm 0.17$ & $1.3 \pm 0.08$ & $13.9 \pm 2.9$ & $15.75 \pm 3.1$ & $19.93 \pm 3.9$ \\
\hline & 0.5 & $0.29 \pm 0.11$ & $1.6 \pm 0.19$ & $13.5 \pm 1.6$ & $17.77 \pm 2.9$ & $22.51 \pm 3.2$ \\
\hline & 0.2 & $0.25 \pm 0.11$ & $1.5 \pm 0.17$ & $11.8 \pm 1.1$ & $23.91 \pm 4.2$ & $30.31 \pm 4.8$ \\
\hline
\end{tabular}


Table 3 Characteristics of AVD and DC photodetectors at a fixed voltage of $30 \mathrm{~V}$

\begin{tabular}{|c|c|c|c|c|c|c|}
\hline & \multicolumn{3}{|c|}{ AVD photodetectors } & \multicolumn{3}{|c|}{ DC photodetectors } \\
\hline $\mathrm{P}$ & Dark current & On/off & Responsivity & Dark current & On/off & Responsivity \\
\hline$\left(\mathrm{mW} \mathrm{cm} \mathrm{cm}^{-2}\right)$ & $(\mathrm{nA})$ & ratio & $\left(\mathrm{A} \mathrm{W}^{-1}\right)$ & $(\mathrm{nA})$ & ratio & $\left(\mathrm{A} \mathrm{W}^{-1}\right)$ \\
\hline 1.5 & & 26.7 & 82.6 & & 2.7 & 5.6 \\
\hline 2.5 & 0.3 & 28.7 & 58.5 & 2.1 & 3.6 & 4.9 \\
\hline 6.5 & & 59.2 & 48.2 & & 5.6 & 3.1 \\
\hline
\end{tabular}


Table 4 Comparison of performance for photodectors based on various semiconductors

\begin{tabular}{|c|c|c|c|c|}
\hline \multirow[b]{2}{*}{ Material } & Wavelength & Power density & Responsivity & \multirow[b]{2}{*}{ Reference } \\
\hline & $(\mathrm{nm})$ & $\left(\mathrm{mW} \mathrm{cm}{ }^{-2}\right)$ & $\left(\mathrm{A} \mathrm{W}^{-1}\right)$ & \\
\hline \multirow{3}{*}{ pentacene } & 365 & 5.0 & 50 & \multirow{3}{*}{62} \\
\hline & & & & \\
\hline & 650 & 5.0 & 0.45 & \\
\hline Spiro-4p-CPDT & 370 & 1 & 25 & 52 \\
\hline С8ВТВТ & 473 & 2.7 & 33 & 63 \\
\hline \multirow{3}{*}{$\mathrm{C}_{60}$} & 360 & 4.38 & 75.3 & \multirow{3}{*}{37} \\
\hline & & & & \\
\hline & 650 & 4.38 & 90.4 & \\
\hline F8T2 & 405 & 3 & 0.0004 & 54 \\
\hline graphene & 532 & 1 & 8.61 & 55 \\
\hline $\mathrm{ZnO} / \mathrm{GaN}$ & 370 & 1 & 1.3 & 57 \\
\hline $\mathrm{ZnO}$ & 382 & 1 & 0.0056 & 56 \\
\hline $\mathrm{In}_{2} \mathrm{Se}_{3}$ & 500 & 2.81 & 89 & 58 \\
\hline $\mathrm{ZnO}-\mathrm{CNT}$ & 365 & 10 & 0.00048 & 59 \\
\hline $\mathrm{NPB} / \mathrm{C}_{60}$ & 350 & 0.192 & 0.315 & 60 \\
\hline AVD-grown $\mathrm{C}_{60}$ & 780 & 1.5 & 82.6 & In this work \\
\hline
\end{tabular}

